\title{
1. Comparative disciplines: an introduction
}

\author{
Maurice Adams
}

\section{COMPARATIVE LAW AS A NON-AUTONOMOUS DISCIPLINE}

For a long time, traditional national legal research has focused on the identification of legal sources ${ }^{1}$ and especially on the interpretation of texts: legislation, treaties, case law, travaux préparatoires, doctrinal texts, and so on. ${ }^{2}$ This has resulted in the type of research in which answering descriptive or so-called doctrinal questions ('What is the state of the law on a certain topic?'), as well as the search for systemic coherence and consistency with regard to these texts, are central activities. Geoffrey Samuel called this the 'authority paradigm' because, in this approach, the authoritative nature of the aforementioned legal texts is emphasized. To be sure, the texts themselves can of course be criticized, but they can never be questioned in terms of their epistemological power. ${ }^{3}$ At most, the system of private, administrative, criminal law, and so on, can be further refined, usually as a result of incidental changes in those areas of law, but always on the basis of the frameworks set by the legal system itself. In addition, the system of the law itself is hardly up for discussion because that is, after all, the point of departure of legal analysis. Legal research thus becomes self-legitimizing, as it were, and law is understood as a fully autonomous discipline.

It is, therefore, no surprise that lawyers often also act in this way when researching and comparing different legal systems or legal configurations.

\footnotetext{
Mostly through a local Grundnorm or rule of recognition.

2 For a nuanced position on legal sources, see recently J. Bell, 'Sources of Law' (2018) 77 Cambridge Law Journal 40-71.

3 See Samuel in this volume. Also G. Samuel, 'Is Law Really a Social Science? A View from Comparative Law' (2008) 67 Cambridge Law Journal 288-321 and G. Samuel, 'Interdisciplinarity and the Authority Paradigm: Should Law Be Taken Seriously by Scientists and Social Scientists?' (2009) 36 Journal of Law and Society 431-59.
} 
Comparative legal research is then understood as an instance of the more general form of legal research as outlined above, and 'the way in which it attempts to reconstruct both the foreign and the researcher's own legal systems is similar to general legal research on either of those systems'. ${ }^{4}$ From the point of view of method, one could, as a result, simply refer to what doing legal research within one's own legal system amounts to, add a few words of warning on the choice of countries and the dangers of translation, and subsequently list the similarities and differences in rules or institutions in the legal systems under review. Indeed, framed like this, it seems as if there is nothing special in doing comparative law. ${ }^{5}$

But law has of course never been a fully autonomous discipline. ${ }^{7}$ The regulation of social order through the interpretation of a variety of authoritative texts always, albeit often subconsciously, brings into play the lawyers' conceptions

4 J. Bell, 'Legal Research and the Distinctiveness of Comparative Law', in M. van Hoecke (ed), Methodologies of Legal Research: Which Kind of Method for What Kind of Discipline (Hart Publishing 2011) 175. To do justice to Bell, I must add that this quote does not fully represent his view on comparative law and legal research. Comparative law, according to Bell, also has to engage with the institutional setting of the legal systems under comparison, i.e., their organization, legal concepts, presuppositions and mental map of the relationships between legal institutions, its legal procedures, and the broader social and cultural context and assumptions.

5 This situation is to some extent comparable to nineteenth-century comparative linguistics, at that time called 'comparative philology'. Robert Lord notes: 'The new science of comparative philology aimed at no more than comparing one language with another, illuminating one language through another, explaining the forms of the one by the forms of the other, rather in the manner that botanists have compared species of flora, noting and classifying according to similarity and divergence' (Comparative Linguistics, The English Universities Press, 1974, at 107-8). He adds: 'Their serious error (and they can hardly be blamed for that) is that in their investigations they never asked themselves the meaning of their comparisons or the significance of the relations they discovered. Their method was exclusively comparative, not historical' (ibid, at 108-9).

6 In this approach the concept of 'law' itself is many times treated as a fixed given. That is particularly problematic for comparatists, because what constitutes law is not more or less similar everywhere. Even stronger, the comparatist's understanding of law is not simply one question among others within a comparative method, but informs methodological choices on all levels of the comparative exercise. M. Adams and J.A. Bomhoff, 'Comparing Law: Practice and Theory', in M. Adams and J.A. Bomhoff (eds), Practice and Theory in Comparative Law (Cambridge University Press 2012) at $8-9$.

K.M. Sullivan, 'Interdisciplinarity' (2002) 100 Michigan Law Review 1220-1. Sullivan adds that this does not make law less of a discipline in its own right: 'If you have any doubt that legal method is distinctive, try reading a non-lawyer's attempt to state the holding of a judicial opinion' (at 1219). 
and ideologies of social reality. ${ }^{8}$ Comparative legal research asks for heightening or making explicit these conceptions and ideologies. ${ }^{9}$ Comparative law, at the same time, also provokes questions that are not only about the lawyers' ideological conceptions of social reality, but also about what counts as similarities or differences, or about how and why a legal culture develops, diffuses, or influences other legal cultures. Answering these questions assumes firm knowledge of a specific domain of the law as such (legal knowledge stricto sensu), but it also requires knowledge about other disciplines. Depending on the specific aims and questions being researched, it has to be answered through a combination of different disciplinary angles: sociology, economics, cultural studies, history, anthropology, and the like.

\section{COMPARATIVE LAW AND COMPARATIVE DISCIPLINES}

Martin Shapiro wrote in 1981 about comparative law that

for the most part it has consisted of showing that a certain procedural or substantive law of one country is similar to or different from that of another. Having made the showing, no one knows quite what to do next. Or, alternatively, comparison consists of presenting descriptions of a number of legal systems side by side, again with no particular end in view. ${ }^{10}$

All too frequently the word 'comparative' in 'comparative legal research' still seems indeed far from being the operative one. In other words: What is the comparative benefit of such exercises? When does comparative law become more than a form of Auslandrechtkunde? Of course, some of the comparative work will already have been carried out when describing foreign law: the comparative researcher will inevitably, although implicitly, reflect on the relation between her own and other legal systems. ${ }^{11}$ But to really compare, something more needs to be done. What is important is to explicitly confront and relate the collected information about the different legal systems or cultures and to form a view on their mutual relationship from the chosen angle. The questions that emerge when doing so are not only relevant for comparative law but are

8 This is also the reason why two identical regulations in different legal systems can have a completely different meaning, as Karl Renner already showed. See his Die Rechtsinstitute des Privatrechts und ihre soziale Funktion (J.C.B. Mohr Verlag 1929).

9 See Chapter 13 paragraph V.

10 M. Shapiro, Courts: A Comparative and Political Analysis (University of Chicago Press 1981), at vii.

11 F. von Benda-Beckmann, 'Ethnologie und Rechtsvergleichung' (1981) 17 Archiv fur Rechts- und Sozialphilosophie 310-29. 
part and parcel of comparative research in general. What are we comparing and why are we doing this? What constitutes a tertium comparationis and what a similarity or a difference? What do they show? Can they be fitted into comparative schedules and, if so, on the basis of what criteria? How is it possible to enter into a dialogue about the systems, cultures, countries, institutions, societies under comparison?

The development to asking questions other than doctrinal ones when doing comparative legal research is only reinforced by the process of globalization, ${ }^{12}$ which provokes questions such as: how do the societal changes that occur as a result of globalization impact on the configuration of legal traditions or cultures; how do these adapt or maintain their distinctiveness; how is law used in (relation to) other legal cultures and traditions; how do new legal configurations become assimilated, rejected or refashioned in a host legal system, and so on. ${ }^{13}$ Explicit comparison forces us to deal with such questions, and a great deal of experience is required for this. ${ }^{14}$ Given the challenges these questions pose, one would expect comparative (legal) scholars more often to enter into debate with scholars from other disciplines, because both in their regular and their comparative versions they seem to be confronted with similar questions and challenges. There is much to learn from each other, and insights from other disciplines and comparative research are therefore not so much a nice-to-have addendum but of the essence, as Ralph Weber writes in his contribution to this volume.

It was thus the aim of the series of seminars of which this volume is the fruit $^{15}$ to try to learn from other comparative disciplines. And, although we did not aim to create a new discipline at a 'higher' level (transdisciplinarity) - that would require comparative law, and probably the other disciplines as well, to

12 With Twining, globalization can loosely be described as the developments and interactions which are making the world more interdependent with respect to ecology, economy, communications, language, politics, and so on. W. Twining, Globalisation and Legal Theory (Cambridge University Press 2000), at 4.

13 H. Muir Watt, 'Globalization and Comparative Law', in M. Reimann and R. Zimmermann (eds), The Oxford Handbook of Comparative Law (Oxford University Press 2006) 589-607; P. Zumbansen, 'Transnational Comparisons: Theory and Practice of Comparative Law as a Critique of Global Governance', in M. Adams and J.A. Bomhoff (eds), Practice and Theory in Comparative Law (Cambridge University Press 2012) 189-90 and M. Adams, 'Comparative Law in a Globalizing World: Three Challenges' (2012) 17 Tilburg Law Review 263-8.

14 My impression is that it is precisely because it is so demanding that some comparative legal research can be situated somewhere between description and interpretation of foreign law, and actual comparison. Such research can of course be valuable, and it is certainly the beginning of a comparison as long as an all-embracing conceptual framework is developed, being an answer to a specific question.

15 See the Preface to this volume. 
be much more developed methodologically and theoretically ${ }^{16}$ - we nevertheless hope that comparative legal research will transcend a pure juxtaposition of perspectives: not just methodologically, when comparing different legal systems or cultures, but also by recognizing at the same time the (many times plural) identity of each discipline involved when trying to answer the type of questions identified above. Comparative legal research may gain important insights from the disciplines that are most prominent in this volume, which is to say, from the humanities and from the social sciences, most notably in their comparative and qualitative (interpretative) versions. ${ }^{17}$

\section{OUTLOOK OF THIS VOLUME}

The chapters presented in this volume range from contrasting comparative legal versus historical approaches to comparative sociology, comparative religion, comparative (legal) anthropology, comparative literature, comparative politics and comparative philosophy.

Geoffrey Samuel makes us aware that in history and legal history, understanding the past in categories of today is a challenge to be resisted. At the same time, none of these disciplines has a neutral perspective with which to analyse or understand other cultures. Samuel presents the theories and debates that are animating history in this regard, and identifies how they are relevant for legal history, for law as a discipline and, of course, for comparative law. Samuel argues that the comparatist as much as the legal historian must be aware of the paradigm orientation within which the research is pursued: is law regarded as something that transcends culture or is it being seen as a cultural phenomenon? Is there an ideological emphasis, such as a Marxist or neoliberal one, a gender framework, or a colonialist emphasis? Ultimately, for Samuel, history, as part of the humanities and social sciences, is subjected to the same epistemological and methodological complexities as any other discipline within this discipline grouping.

16 In such a 'transdisciplinary' approach, one tries to leave behind the specific perspectives of each discipline and to construct a new conceptual and theoretical framework at a higher level. This comes close to what Ost and Van de Kerchove have called a scientific Esperanto: F. Ost and M. van de Kerchove, 'Towards an Interdisciplinary Theory of Law', in A. Peczenik (ed), Theory of Legal Science (Kluwer International 1984) 503-7 and F. Ost and M. van de Kerchove, 'Avant-propos: pour une épistémologie de la recherche interdisciplinaire en droit' (1982-3) Revue interdisciplinaire d'études juridiques $1-7$.

17 The relation between qualitative and interpretative approaches on the one hand, and more quantitative or external approaches on the other, is explicitly discussed in this volume, for example by Van der Veer and Nelken. See also the chapter by Wong on comparative politics. 
In addition to Samuel's chapter, Kjell $\AA$ Modéer sketches an intellectual history of comparative legal history, and especially its transformation from the post-Second World War universalistic legal paradigm, with a focus on similarities, into the global diversity, with a focus on differences. His survey of the history of the relationship between comparative law and legal history demonstrates that current research within the dynamic field of comparative law offers multiple theories and methods. What emerges from his overview is that the main aim of comparison cannot, and must not, be about right or wrong answers. It is rather about creating sensitivity for the different contexts of the law (in his case, he is building on professional experiences in Sweden as well as Vietnam).

Jean-Pascal Daloz's contribution is constructed around his research on the sociology of elite distinction. He notes that sociology has remained a discipline with strong rivalries between more or less conventional schools of thought. Comparative explorations can, as a result, be understood in terms of an extended playground for these schools of thought. He too notes that any comparative work entails serious risks of ethnocentrism, over-generalization, undue extrapolation, rigid assumptions, and dubious deductive reasoning. Daloz shows how it is possible to avoid these challenges by advocating an eclectic inductive methodology, in which appealing to the authority of conventional models of interpreting differences between societies can only make sense in a particular context without giving a priori explanatory precedence to any of them. This requires sufficient open-mindedness to be able to recognize those cases for which new theorizing, or at least a revision of existing theories, is required. Daloz takes a cautious stance toward explanatory concepts with a universalistic ring and toward the grand theories that rely on them, and encourages comparative studies that are attentive to local perceptions. The comparatist, one might say, should as a result permanently work in a 'spirit of conceptual tentativeness': the researcher needs to avoid normative preconditions as much as possible and be willing to replace the original conceptual and comparative framework with a better-suited one. Comparative analysis thus leads to a better recognition not only of convergent trends and processes but also of dissimilar scenarios, and even occasional pairs of cases that constitute almost complete reversals of one another.

From the early days of the academic study of religion, Freiberger notes in his chapter, comparison has been an important feature of the discipline. But while scholars frequently speak of 'the comparative method', they seem to be more interested in the adjective ('comparative') than in the noun ('method'). As a result, how comparison actually works as a method in the study of religion has not been discussed in greater detail so far. Freiberger proposes a methodological frame of comparison that addresses both the general configuration of a comparative study - its goal, mode, scale and scope - and the comparative 
process, separating operations of selection, description and analysis, juxtaposition and redescription, as well as rectification and theory formation. He argues that identifying and analysing such elements of a comparative methodology helps, on the one hand, to evaluate existing comparative studies, and on the other, to produce new ones. Freiberger moreover argues that comparison often serves as a research design rather than a research method, and, moreover, that comparison is so fundamentally embedded in most research methods that it can hardly be recognized as a separate method.

In her chapter on comparative methods in legal anthropology, Katrin Seidel offers an overview of what comparative law can gain from anthropological insights. She focuses on the mutual influence of different socio-legal cultures by looking at how to grasp the constant meeting of different normative understandings, particularly when global, national and local dimensions are revealed. For her, a thoughtful contextualization of this dynamics invites what Clifford Geertz has famously coined 'thick comparison'. For this, cultural translation is advocated to better understand the mutual influence and constant transformation of socio-legal cultures. In a similar vein to what Daloz concludes, Seidel acknowledges that what can be learned from one case is not necessarily comparable with what can be learned from another (even though, as she puts it, zones of comparison in the sense of an arena of reflection may be developed). Furthermore, Seidel's chapter not only provides a criticism of traditional comparative approaches but also draws on the author's research to provide a glimpse into the dynamics of international rule of law promotion in practice, as well as giving an empirical example from South Sudan's ongoing internationalized constitution-making. It thus also invites us to rethink our conceptions of state(hood), governance and legitimacy in light of global legal pluralism.

For Van der Veer the comparative advantage of anthropology is that it first and foremost engages with difference and diversity among cultures and societies and focuses on problems of cultural translation. As such, it can offer a critique of the universalization of Western models of social life. Moreover, through the close study of a fragment one is able to comment on the larger whole, and an understanding of precisely this larger whole allows one to interpret the fragment. Anthropology thus offers, according to Van der Veer, greater potential for social science than the analysis of large data, undergirded by game theory and rational choice theory. It might better remedy the pervasiveness of ethnocentrism in the social sciences (a danger that is identified in most of the chapters in this volume). Comparative anthropology is as a result able to question the universality of what in Western society and languages is taken to constitute the separate domains of the economy, of politics, of law, and of religion as well as the dichotomy between state and society or between the individual and society. The holistic perspective of anthropology that Van 
der Veer advocates allows us to bracket these assumptions and investigate how people outside of the modern West are conceptualizing their social life.

In one of the few contributions to this volume on an essentially quantitative discipline, Mathew Wong writes about comparative politics. He provides an overview of the key concepts and methods in comparative politics, and takes a strikingly different perspective from the other contributions. Wong points out that small-N studies or case studies are strongly criticized in his discipline. Comparative politics scholars deal almost exclusively, according to Wong, on questions of 'whether' and 'why': whether democracies produce a superior economic performance to dictatorships; why authoritarian regimes democratize. However, questions of 'should' are seldom touched upon in comparative politics, and neither are value-based judgements: should Country A democratize? Should every country have a just political system? These questions are, according to Wong, taken up by political philosophers and political theorists. Wong points out that research questions in comparative politics are nowadays often theorized as causal relationships, that is, how X (the cause) affects Y (the consequence). As a result, methodological evolution and innovation in the field of comparative politics are limited to the choice of tools used to uncovering causal relationships. It was moreover only in recent decades that comparative politics started to take comparison seriously, with the introduction of comparative case studies (small-N) and statistical studies (large-N). The recent rise of such experimental methods is nevertheless no exception to the methodological tradition: they are part and parcel of the pursuit for truly causal inferences.

Ralph Weber, in his chapter on comparative philosophy, states that, like every academic discipline, comparative philosophy is a practice that has its own history. At present, comparative philosophy is lively and the field is diverse and assembles different, sometimes even contradictory views. Weber presents these different views and then proceeds to deal with the current conceptualization of the logic of comparison, with specific attention to diminishing bias and the adequacy of bases of comparison. Weber helpfully states that one way of investigating the inner dynamics of a given comparison is to ask a set of questions: Who is performing the comparison? What commonality supports the choice of what has to be compared? What is being compared with what? In what respect(s) does the comparer compare that which they compare? What relation results from comparing what the comparer compares in that particular respect? How does the choice of the pre-comparative tertium restrict the realm of possible tertia comparationis? How does a chosen tertium comparationis qualify the comparanda? And what role does the comparanda play in the result of the comparison? Each of these questions reveals an enormous complexity, and the answers may be subject to criticism or require further clarification and substantiation. Moreover, most if not all of these questions are 
highly relevant for comparative legal research too. The chapter also deals with some specific issues, such as generalization, one-sidedness and the identification of similarities and differences.

David Nelken deals with the question of what makes a good comparison and how we judge what represents such a comparison in practice. He attempts to make progress with regard to this debate by focusing on the relationship between comparing and commensuration, both activities which can be found in everyday social processes, academic enquiries and professional technical activities. To say that something is comparable, Nelken writes, is to assert that it is possible to be compared. To say that it is commensurate is more to claim that something is of a proportionate or similar measurable standard. Comparison is a pursuit aimed at explaining and understanding. It requires knowing as much as possible about the matters being compared so as to highlight both the similarities and differences. Commensuration, being more of a pursuit aimed at practical goals such as homogenizing, ranking or coordinating, is however only interested in demonstrating what is or should be similar despite differences. Commensuration thus runs the risk of imposing common measures on matters which would otherwise be considered dissimilar. After ascertaining that what counts as a 'good enough comparison' will depend on the purpose at hand, Nelken then links this to research on global social indicators. Given the fact that commensuration is often related to practical policies and thus serves as a nexus to power and knowledge, he deals with the larger debate over the different ways that have been proposed to improve the accuracy and legitimacy of global social indicators. Nelken stresses that what is important is to know the limits of such qualitative and quantitative indicators to comparison and in knowing where and how human judgement and political contestation should enter the scene.

Angus Nicholls presents an intellectual history of the British tradition of comparative literature, which has strong German roots. He stresses that comparisons are never neutral, and are culturally and temporarily contingent. Nevertheless, for quite some time the discipline has been marked by a sense of 'universalism', mostly informed by Eurocentric - genre-related, aesthetic, cultural - selection criteria for comparison. This universalism stimulates the use of similarity as the main component of comparison, and suppresses the differences between linguistic and cultural traditions. From a meta-comparative point, two processes of comparison, which Nicholls emphasizes by contrasting the work of Friedrich Max Muller and Goethe, can be distinguished: the first is a method that begins with empirical observations and goes on to construct heuristic ideal types, which may later be revised or adjusted depending on subsequent experience; the second assumes a priori an ideal commonality that is later seen to be confirmed through empirical observations. The weakness of the first method may be a lack of any consistent guiding model or hypothesis 
through which empirical observations could be ordered. The weakness of the second method may be that the assumed commonality or identity will tend to influence the selection of materials and the observations made. The first method would tend to emphasize difference and would therefore coincide with what Nicholls calls particularism, whereas the second would stress similarity and coincides with what he calls universalism. Nicholls adds that both models must be held in tension with one another. That could result in a "negative dialectics' of cultural comparison, that is, a comparison in which neither of the two positions can be regarded as foundational.

In his chapter, Mark Van Hoecke tries to answer some of the topics that are discussed by the contributors to this volume: What is meant by comparing? What are the theoretical frameworks relied upon by comparative disciplines? Is a common scientific (meta)language possible across cultures and disciplines? What about a 'tertium comparationis' to be used for comparing? What about culturalism or universalism, or quantitative or qualitative methods? $\mathrm{He}$ concludes that translation is at the core of any comparative (and interdisciplinary) method. He also concludes that the principal advantage of comparative research is that it leads, or at least could lead, to a reflection on one's own conceptual framework and its underlying assumptions.

In the final chapter Maurice Adams and Mark Van Hoecke draw some more general conclusions, especially with regard to the challenges that lie ahead, not just for comparative legal research, but for comparative disciplines as such. Considering the many challenges that are identified and discussed in this volume, the editors conclude that comparative research can especially be further developed when it also is understood as a research design, instead of just a method. 